\title{
Effect of Meteorological Conditions on Pollutants Removal and Enhancing Approaches During Photovoltaic Energy Direct Application: Electrokinetic Remediation of Soil Containing Cr(VI) as an Example
}

Shunxi Zhang, Xiaohong Yang, Xianzhong Cheng, Chun Hu, Bo Chai, Jianfen Li, Yunjun Mei*

School of Chemical and Environmental Engineering, Wuhan Polytechnic University, Wuhan, 430023, Hubei, China

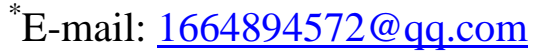

doi: $10.2016 / 2016.07 .01$

Received: 14 March 2016 / Accepted: 29 April 2016 / Published: 4 June 2016

To explore the effect of meteorological conditions on pollutants removal and enhancing removal efficiency approaches in weak solar irradiation intensity during photovoltaic energy direct application, electrokinetic remediation of soil containing $\mathrm{Cr}(\mathrm{VI})$ was investigated as an example. The results show that meteorological conditions have a significant effect on pollutants removal, and $\mathrm{Cr}(\mathrm{VI})$ removal efficiency for a sunny day is the highest. $\mathrm{Cr}(\mathrm{VI})$ concentration and total $\mathrm{Cr}$ concentration in the different layer suggest that chromium in soil is electromigrated and accumulated near the anodic region. Total $\mathrm{Fe}$ concentration implies that the anodic product $\mathrm{Fe}^{2+}$ is migrated into the cathode. Energy conversion efficiency for a sunny day is the highest and is $10.4 \%$. However, energy utilization efficiency for an overcast day is the highest, and $E_{m}$ and $E_{v}$ are $24.1 \mathrm{kWh} / \mathrm{kg}$ and $38.3 \mathrm{kWh} / \mathrm{m}^{3}$, respectively. In weak solar irradiation intensity of $37 \pm 3.5 \mathrm{~W} / \mathrm{m}^{2}$, the parallel connection of photovoltaic panels is a feasible approach to enhance pollutants removal, and in 30min $\mathrm{Cr}(\mathrm{VI})$ removal efficiency for four panels can rise to $79.8 \%$ from $64.3 \%$ for only one panel. The extending reactive time is also a feasible way, and removal efficiency for one panel can increase from $64.3 \%$ to $80.7 \%$ as time prolonging from $30 \mathrm{~min}$ to $60 \mathrm{~min}$.

Keywords: Meteorological conditions, Photovoltaic energy, Pollutants removal, Enhancing approaches, Soil containing $\mathrm{Cr}(\mathrm{VI})$

\section{$\underline{\text { FULL TEXT }}$}


(C) 2016 The Authors. Published by ESG (www.electrochemsci.org). This article is an open access article distributed under the terms and conditions of the Creative Commons Attribution license (http://creativecommons.org/licenses/by/4.0/). 